\title{
Anaplasma infection of Bactrian camels (Camelus bactrianus) and ticks in Xinjiang, China

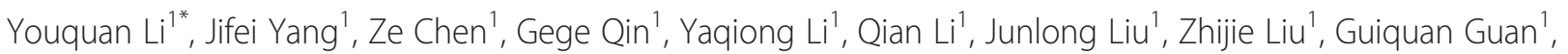
Hong Yin ${ }^{1,2}$, Jianxun Luo ${ }^{1}$ and Lin Zhang ${ }^{1}$

\begin{abstract}
Background: To date, anaplasmosis has been reported to be a subclinical disease in Indian and Arabian one-humped camels (Camelus dromedarius) and llamas (Lama glama). However, no information on Anaplasma infection in two-humped Bactrian camels (Camelus bactrianus) in China has been published to date. The aim of this study was to investigate the prevalence of Anaplasma spp. in domestic Bactrian camels and ticks in Xinjiang, China.

Findings: A total of 382 ticks were collected from the Bactrian camels and from environmental sources. Of these, 84 were morphologically identified as belonging to the Rhipicephalus sanguineus group and genetically identified (12S rDNA, 16S rDNA and the cytochrome c oxidase 1 genes) as $R$. sanguineus group ticks (temporally designated as Rhipicephalus sp. Xinjiang). PCR testing showed that $7.2 \%$ (20/279) of the camels harbored Anaplasma platys DNA. However, microscopic examination revealed no A. platys inclusions in blood smears from the camels. The PCR prevalence of A. platys DNA was $9.5 \%$ (6/63) in Rhipicephalus sp. Xinjiang from the Bactrian camels and $14.3 \%(3 / 21)$ in Rhipicephalus sp. Xinjiang from the vegetation. A. platys DNA was not detected by PCR in other tick species (Hyalomma asiaticum, Dermacentor niveus and Hyalomma dromedarii), and no other Anaplasma species were detected in these samples.
\end{abstract}

Conclusions: This is the first report of A. platys in Bactrian camels in Xinjiang, China. The moderate positivity observed indicates that these animals might be a natural host for this pathogen in China.

Keywords: Anaplasma platys, Detection, Bactrian camel, PCR, Xinjiang, China

\section{Background}

Anaplasmosis is an infectious disease caused by a Gramnegative obligate intracellular bacterium of the Anaplasmataceae family (order Rickettsiales). The order was reclassified in 2001 and includes several genera, including Anaplasma, Ehrlichia, Neorickettsia, and Wolbachia [1]. These arthropod-transmitted bacteria are important emerging pathogens of both animals and humans [2]. Of the known Anaplasma spp., Anaplasma marginale is the most virulent, and is responsible for extensive economic losses to farmers in tropical and subtropical areas [3-5]. A. marginale is considered capable of infecting dromedaries, cervids, domestic buffalos and cattle [6-9]. A. phagocytophilum is the causative agent of human granulocytic

\footnotetext{
* Correspondence: youquan-li@163.com

${ }^{1}$ State Key Laboratory of Veterinary Etiological Biology, Key Laboratory of Veterinary Parasitology of Gansu Province, Lanzhou Veterinary Research Institute, Chinese Academy of Agricultural Sciences, Lanzhou 730046, P. R. China

Full list of author information is available at the end of the article
}

anaplasmosis [10, 11], a life-threatening disease associated with high mortality rates in humans; A. phagocytophilum can also infect dromedaries, llamas, and cervids [7, 12]. $A$. platys, the causative agent of canine infectious cyclic thrombocytopenia, is usually a mild disease with a worldwide distribution, although its virulence may vary from region to region $[13,14]$. A. platys is supposed to be transmitted by $R$. sanguineus sensu lato $[15,16]$. Nonetheless, a definitive proof of the vector competence of this tick for A. platys is currently lacking [17].

The genus Camelus includes two species: Camelus dromedarius, a dromedary or one-humped camel, and Camelus bactrianus, a Bactrian or two-humped camel. Currently, there are around 160,000 Bactrian camels in Xinjiang, China, but dromedary camels are wild and there are no accurate statistics about them [18]. Anaplasmosis in camels is reported to be a subclinical disease in Tunisian, Indian and Arabian one-humped camels [7, 19-24]. To date, only A. marginale and A. phagocytophilum have been reported to cause anaplasmosis in dromedaries and llamas 
[7, 19-24]. Information on canine, bovine, ovine, caprine and cervine anaplasmosis has been recorded [25-28], but no information on anaplasmosis in camels in China is available. The aim of this study was to investigate the prevalence of Anaplasma species in domestic Bactrian camels and ticks in Xinjiang, China.

\section{Methods \\ Sample collection}

The region investigated in Xinjiang, China is located at latitudes $39^{\circ} 30^{\prime}$ to $41^{\circ} 27^{\prime}$ north and longitudes $79^{\circ} 39^{\prime}$ to $82^{\circ} 01^{\prime}$ east. The study was performed in May 2014. In total, 279 blood samples were randomly collected from free-choice grazing camels in desert regions. Blood smears were prepared from blood samples obtained by ear venipuncture of individual Bactrian camels. All of camels were clinically examined before blood sample collection.

Ticks on camels were collected directly and transferred to labeled vials, whereas dragging was used to collect ticks from the vegetation [29]. This method is considered inefficient for sampling Hyalomma spp. ticks because they are concealed in favorable micro-habitats and display an active host-seeking behavior [30]. Thus, Hyalomma spp. were collected from the walls and crevices of camel sheds. Three hundred and eighty-two ticks were collected from camels, environment vegetation, and animal sheds. All ticks were labeled according to their sources (i.e., camel, vegetation or animal shed), and were morphologically identified according to the methods of Teng and Jiang [31]. Ticks belonging to the $R$. sanguineus group $(n=84)$ were subject to further identification using the methods of Dantas-Torres et al. [32]; these methods are based on PCR amplification and sequence analysis of the $12 \mathrm{~S} \mathrm{rDNA}, 16 \mathrm{~S} \mathrm{rDNA}$, and cytochrome c oxidase $(\operatorname{cox} 1)$ genes. PCR products of three genes were purified and ligated into pGEM T easy vector. The recombinant plasmids were transformed into Escherichia coli DH5 $\alpha$ competent cells. As for each PCR samples, at least three positive clones identified by their own relative specific primers were sequenced by the GenScript Corporation (NJ, China). Basic Local Alignment Search Tool software (http://blast.ncbi.nlm.nih.gov/ Blast.cgi?CMD=Web\&PAGE_TYPE=BlastHome) was used for sequence analysis. Representative $12 \mathrm{~S}$ and $16 \mathrm{~S}$ rDNA genes and cox 1 gene nucleotide sequences have been deposited in GenBank.

\section{Microscopy}

Blood smears were air-dried, fixed in methanol, stained with a $10 \%$ solution of Giemsa (Sigma-Aidrich, Santa Clara, CA, USA) in phosphate-buffered saline ( $\mathrm{pH} 7.2$ ), and then subjected to microscopic examination.

\section{DNA extraction}

After species identification, all the ticks were washed in $70 \%$ ethanol, rinsed three times in sterile phosphatebuffered saline, and dried on filter papers. They were separated individually and stored at $-80{ }^{\circ} \mathrm{C}$ until the DNA extraction. Genomic DNA from 279 whole blood samples and 382 of the tick samples was extracted individually using DNeasy Blood \& Tissue Kit (Qiagen, Hilden, Germany) according to the manufacturer's instructions. DNA yields were determined using a NanoDrop ND-2000 Spectrophotometer (Nanodrop Technologies, Wilmington, DE, USA).

\section{Molecular detection of Anaplasma spp. using species- specific primer sets}

PCR was used to detect and identify Anaplasma spp. from Bactrian camels and ticks using the genera-specific and species-specific primers listed in Table 1 [16, 33-35]. PCR reactions were performed in a DNA thermocycler (BioRad, Hercules, CA, USA) and the PCR conditions were the same as those reported previously [16, 33-35]. DNA from ovine whole blood without Anaplasma and Ehrlichia DNA and DNA from each bacterial species were included in each PCR reaction as negative and positive controls; of positive control, A. platys DNA originated from dog, $A$. ovis DNA from goat, $A$. marginale DNA from cattle, $A$. bovis DNA and $A$. phagocytophilum DNA from red deer. To assess the presence of specific bands for Anaplasma spp., PCR products were separated by $1.5 \%$ agarose gel electrophoresis and the purified DNA products were sequenced. Only when the PCR and sequencing results were consistent were the samples identified as positive for Anaplasma spp. Representative sequences of the newly identified pathogens have been deposited in GenBank.

\section{Ethical approval}

This study was approved by the Animal Ethics Committee of the Lanzhou Veterinary Research Institute, CAAS (No. LVRIAEC2013-010). Use of the field samples was approved by the Committee on Animal Research and Ethics of China.

\section{Findings}

\section{Tick identification}

The 382 ticks identified herein included the following four species: Hyalomma asiaticum ( $n=186,154$ adults from camels and 32 adults from animal sheds), $R$. sanguineus group $(n=84,63$ adults from camels and 21 adults from vegetation), Dermacentor niveus $(n=60,42$ adults from camels and 18 adults from vegetation), and Hyalomma dromedarii ( $n=52,39$ adults and 2 nymphs from camels, and 11 adults from animal sheds) (Table 2). Ticks morphologically identified as belonging to the $R$. sanguineus group were also genetically characterized as 
Table 1 Sequences of the primers used in this study

\begin{tabular}{|c|c|c|c|c|c|}
\hline \multirow[t]{2}{*}{ Pathogen } & \multirow[t]{2}{*}{ Target gene } & \multicolumn{2}{|l|}{ Primers } & \multirow[t]{2}{*}{ Final amplicon size (bp) } & \multirow[t]{2}{*}{ Reference } \\
\hline & & Primer name & Oligonucleotide sequences $\left(5^{\prime}-3^{\prime}\right)$ & & \\
\hline \multirow[t]{2}{*}{ Anaplasma \& Ehrlichia } & $16 \mathrm{~S}$ rRNA & EC9 & TACCTTGTTACGACTT & 1462 & [33] \\
\hline & & EC12A & TGATCCTGGCTCAGAACGAACG & & \\
\hline \multirow[t]{2}{*}{ A. bovis } & $16 \mathrm{~S}$ rRNA & AB1f & CTCGTAGCTTGCTATGAGAAC & 551 & [33] \\
\hline & & $A B 1 r$ & TCTCCCGGACTCCAGTCTG & & \\
\hline \multirow[t]{2}{*}{ A. phagocytophilum } & $16 \mathrm{~S}$ rRNA & SSAP2f & GCTGAATGTGGGGATAATTTAT & 641 & [33] \\
\hline & & SSAP2r & ATGGCTGCTTCCTITCGGTTA & & \\
\hline \multirow[t]{2}{*}{ A. marginale } & msp4 & Amargmsp4 F & CTGAAGGGGGAGTAATGGG & 344 & [34] \\
\hline & & Amargmsp4 R & GGTAATAGCTGCCAGAGATTCC & & \\
\hline \multirow[t]{2}{*}{ A. ovis } & msp4 & Aovismsp4 F & TGAAGGGAGCGGGGTCATGGG & 347 & [34] \\
\hline & & Aovismsp4 R & GAGTAATTGCAGCCAGGGACTCT & & \\
\hline \multirow[t]{6}{*}{ A. platys. } & $16 \mathrm{~S}$ rRNA & PLATYS F & AAGTCGAACGGATTITTGTC & 506 & [16] \\
\hline & & PLATYS R & CTITAACTTACCGAACC & & \\
\hline & groEL & PLA-HS475F & AAGGCGAAAGAAGCAGTCTTA & 724 & {$[35]$} \\
\hline & & PLAT-HS1198R & CATAGTCTGAAGTGGAGGAC & & \\
\hline & $g / t A$ & PLA-CSM136F & TTGCAAAAAGTAAGCGGAGC & 1459 & {$[35]$} \\
\hline & & PLA-CS1359R & AACCACAGGCTTATGACAAC & & \\
\hline
\end{tabular}

R. sanguineus group ticks and temporally designated as Rhipicephalus sp. Xinjiang. The nucleotide sequences reported in this article have been deposited in GenBank (12S rDNA: KR809575-KR809580; 16S rDNA: KR809581KR809588; cox1: KR809589-KR809595). All R. sanguineus group ticks isolates in the present study shared $99.8 \%-$ $100 \%$ identity in their $12 \mathrm{~S}$ rDNA gene sequences, $100 \%$ identity in $16 \mathrm{~S}$ rDNA and cox 1 gene sequences. As compared with sequences available in Genbank, the highest sequence identities were found with sequences labeled as $R$. turanicus from USA. However, compared with a reference sequences of $R$. turanicus from Turkmenistan they showed identity of 96.2-96.5\% for $12 \mathrm{~S}$ gene (GenBank accession number: KF145151), $95.3 \%$ for $16 \mathrm{~S}$ gene (GenBank accession number: KF145150) and $90.5 \%$ for cox 1 gene (GenBank accession number: KF145153).

\section{Microscopic examination of blood smears}

No obvious suspected cases of anaplasmosis were observed based on the signs of fever, anemia, emaciation, slight ataxia, and anorexia in the geographical region we investigated. No microscopic evidence of Anaplasma infections in the blood smears from the Bactrian camels was observed.

Table 2 Prevalence of Anaplasma spp. in Bactrian camels (Camelus bactrianus) and ticks in Xinjiang, China (2014)

\begin{tabular}{|c|c|c|c|c|}
\hline \multirow[t]{2}{*}{ Host } & \multirow[t]{2}{*}{ No. of samples } & \multicolumn{3}{|c|}{ Prevalence of Anaplasma spp. by PCR } \\
\hline & & A. platys & A. marginale & A. phagocytophilum \\
\hline Bactrian camel & 279 & $7.2 \%(20 / 279)$ & 0 & 0 \\
\hline Rhipicephalus sp. ${ }^{b}$ & 21 & $14.3 \%(3 / 21)$ & 0 & 0 \\
\hline Rhipicephalus sp. ${ }^{c}$ & 63 & $9.5 \%(6 / 63)$ & 0 & 0 \\
\hline Hy. asiaticum ${ }^{d}$ & 32 & 0 & 0 & 0 \\
\hline Hy. asiaticum ${ }^{c}$ & 154 & 0 & 0 & 0 \\
\hline D. niveus ${ }^{\mathrm{b}}$ & 18 & 0 & 0 & 0 \\
\hline D. niveus ${ }^{c}$ & 42 & 0 & 0 & 0 \\
\hline Hy. dromedarii ${ }^{d}$ & 11 & 0 & 0 & 0 \\
\hline Hy. dromedarii ${ }^{\mathrm{a}, \mathrm{c}}$ & 41 & 0 & 0 & 0 \\
\hline
\end{tabular}

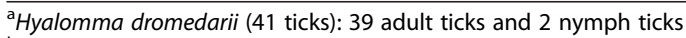

bicks collected from vegetation

${ }^{\mathrm{C}}$ Ticks collected from Bactrian camels

${ }^{\mathrm{d}}$ Ticks collected from walls and crevices of animal sheds 


\section{PCR detection of Anaplasma using species-specific primer sets}

The nearly full-length $16 \mathrm{~S}$ rRNA gene sequences for $A$. platys were 1456 bp using EC9/EC12A primers, which are specific for Anaplasma and Ehrlichia spp. The accession numbers of the 16S rRNA gene sequences are KM246797-KM246800 and KP939254-KP939256 (Anaplasma). For the $16 \mathrm{~S}$ rRNA gene, PCR products of $506 \mathrm{bp}$ were obtained for $A$. platys using the species-specific PLATYS F and PLATYS R primers (GenBank accession numbers: KP939260-KP939262). For the groEL gene, PCR products of $724 \mathrm{bp}$ were obtained for $A$. platys using species-specific PLA-HS475F and PLA-HS1198R primers (GenBank accession numbers: KR011925 and KR011926). For the gltA gene, PCR products of $1459 \mathrm{bp}$ were obtained for A. platys using species-specific PLA-CSM136F and PLA-CS1359R primers (GenBank accession numbers: KR011927 and KR011928). The prevalence of $A$. platys in Bactrian camels and ticks was estimated from the number of PCR-positive samples based on the $16 \mathrm{~S}$ rDNA gene, the groEL gene and the gltA gene, and the three speciesspecific primer sets produced results that were consistent for the prevalence of $A$. platys in Bactrian camels and ticks. The PCR data revealed that the prevalence of $A$. platys in camels was $7.2 \%(20 / 279)$. The prevalence of $A$. platys in Rhipicephalus sp. Xinjiang collected from Bactrian camels was $9.5 \%$ (6/63), while in Rhipicephalus sp. Xinjiang from the environment was $14.3 \%(3 / 21)$ (Table 2). A. platys DNA was not detected in Hy. asiaticum $(n=186)$, D. niveus $(n=60)$, and Hy. dromedarii $(n=52)$. Other Anaplasma spp. (A. phagocytophilum, A. marginale, $A$. bovis and $A$. ovis) were not detected, neither in camels nor in ticks.

\section{Discussion}

To the best of our knowledge, this study is the first to report on the prevalence of Anaplasma infection Bactrian camel in China. The three species-specific primer sets for $A$. platys (based on the $16 \mathrm{~S}$ rDNA gene, the groEL gene and the gltA gene) gave consistent PCR results, confirming the occurrence of $A$. platys in Bactrian camels and ticks. The highest prevalence of $A$. platys occurred in Rhipicephalus sp. Xinjiang ticks collected from the environment and in Rhipicephalus sp. Xinjiang from Bactrian camels; these camels had the lowest prevalence of $A$. platys infection. As far as we know, this is the first report of $A$. platys infection of Bactrian camels worldwide. To date, two other Anaplasma spp., A. marginale and $A$. phagocytophilum, have been associated with anaplasmosis in dromedaries and llamas [7, 19-22]. However, A. marginale and A. phagocytophilum were not detected in the Bactrian camels and four species of ticks that we studied in Xinjiang, China. Other Anaplasma spp., such as $A$. ovis and $A$. bovis, were also not detected in our samples. Anaplasmosis is reported to be a subclinical disease in Tunisian, Indian, and Arabian onehumped camels [20-24]. In the present study, A. platys infections were detected by PCR but there were no obvious signs of anaplasmosis (fever, progressive anemia, generalized lymph node enlargement, emaciation, slight ataxia and anorexia) in the Bactrian camels. One possible explanation for this finding is that A. platys infections in camels show only minimal or no subclinical signs. Dromedary camels are wildlife in Xinjiang, but samples from these animals were not collected in this study; hence, information on anaplasmosis in dromedary camels is not available.

A. platys infects mainly dogs, and cases of canine anaplasmosis have been reported in many countries [13-17, 25, 35]. A. platys infections have been reported in dogs in southern China [25], but the tick species that transmit it have not been determined as yet. Recently, an infection with $A$. platys was detected in a cat in Brazil [36], and infections with this bacterium have also been detected in goats [26] and red deer in China [28]. DNA from $A$. platys was also detected in red foxes [37], in a veterinarian with clinical anaplasmosis [38], and in two women from Venezuela [39]. These data indicate that $A$. platys bacteria have a broad host range. However, the ability of $A$. platys to act as a zoonotic pathogen has not been established; hence, further studies are necessary to determine its zoonotic potential.

Detection of $A$. platys in the moderate number of the Bactrian camels sampled herein indicates that these animals are exposed to the bacterium and that a desert life cycle for this pathogen is possible for camel populations in Xinjiang, China. Therefore, Bactrian camels might play a role in the transmission of this pathogen, possibly by serving as natural hosts. Additionally, because $A$. platys infections have been reported previously in dogs, we speculate that, in Xinjiang, A. platys infections in Bactrian camels might be transmitted from ticks fed on naturally infected dogs. In the desert region of Xinjiang, the animals that cohabitate with Bactrian camels include dogs, wolves, foxes and rabbits. Dogs are a natural host of $A$. platys. However, additional studies will be needed to determine whether wolves, foxes and rabbits can be infected by $A$. platys. Furthermore, PCR detected DNA from $A$. platys in Rhipicephalus sp. Xinjiang ticks collected from Bactrian camels and in local vegetation. Several studies have reported the presence of $A$. platys DNA in $R$. sanguineus group ticks; hence, this pathogen is supposed to be transmitted by $R$. sanguineus group ticks $[15,16,40]$. The finding of $A$. platys DNA in Rhipicephalus sp. Xinjiang ticks raises important questions regarding their role as vectors of $A$. platys for camels in Xinjiang, China. 


\section{Conclusion}

This is the first report to demonstrate the occurrence of A. platys in Bactrian camels in Xinjiang, China. The moderate prevalence of $A$. platys we observed in Bactrian camels indicates that they might be a host for this pathogen in desert regions.

\section{Competing interests}

The authors declare that they have no competing interests.

\section{Authors' contributions}

YL, LZ and GG collected the samples; GQ, YAL, QL and ZC identified the ticks and extracted DNA from whole blood samples and ticks; YL, YJ, and $J \mathrm{~L}$ performed the molecular genetic studies; $Y L, J L$, and $H Y$ drafted the manuscript. All authors have read and approved the final manuscript.

\section{Acknowledgements}

This study was financially supported by the Natural Science Foundation of China (Nos. 31272556, 31372432, 31101621, 31201899), ASTIP, FRIP (2014ZL010), CAAS, Creative Research Groups of Gansu Province (No. 1210RJIA006), "948"(2014-S05), NBCITS (CARS-38), Special Fund for Agroscientific Research in the Public Research (No. 201303035, No. 201303037), MOA, 973 Program (2010CB530206), Basic Research program (CRP No. 16198/ R0), Supporting Program (2013BAD12B03, 2013BAD12B05), Specific Fund for Sino-Europe Cooperation, MOST, China, State Key Laboratory of Veterinary Etiological Biology Project. We thank Edanz Group for help with modifying the paper.

\section{Author details \\ ${ }^{1}$ State Key Laboratory of Veterinary Etiological Biology, Key Laboratory of Veterinary Parasitology of Gansu Province, Lanzhou Veterinary Research Institute, Chinese Academy of Agricultural Sciences, Lanzhou 730046, P. R. China. ${ }^{2}$ Jiangsu Co-innovation Center for Prevention and Control of Important Animal Infectious Diseases and Zoonoses, Yangzhou 225009, P. R. China.}

Received: 31 March 2015 Accepted: 2 June 2015

Published online: 10 June 2015

\section{References}

1. Dumler JS, Barbet AF, Bekker CPJ, Daseh GA, Palmer GA, Ray SC. Reorganization of genera in the families Rickettsiaceae and Anaplasmataceae in the other Rickettsiales: unification of some species of Ehrlichia with Anaplasma, Cowdria with Ehrlichia and Ehrlichia with Neorickettsia, descriptions of six new species combinations and designations of Ehrlichia phagocytophila. Int Sys Evol Microbiol. 2001;51:2145-65.

2. Parola P, Labruna MB. Tick-borne rickettsioses in America: unanswered questions and emerging diseases. Curr Infect Dis Rep. 2009;11(1):40-50.

3. Aktas M, Altay K, Dumanli N. Molecular detection and identification of Anaplasma and Ehrlichia species in cattle from Turkey. Ticks Tick Borne Dis. 2011;2(1):62-5.

4. Kocan KM, de la Fuente J, Blouin EF, Coetzee JF, Ewing SA. The natural history of Anaplasma marginale. Vet Parasitol. 2010;167(2-4):95-107.

5. Aktas M, Özübek S, Altay K, Ipek ND, Balkaya I, Utuk AE, et al. Molecular detection of tick-borne rickettsial and protozoan pathogens in domestic dogs from Turkey. Parasit Vectors. 2015:8:157.

6. Callow LL. Protozoan and rickettsial diseases. In: 'Animal health in Australia'. Canberra: Australian Bureau of Animal Health; 1984. p. 123-86. ISBN 15.

7. Wernery U, Kaaden OR. Infectious diseases of camelids. Berlin: Blackwell Science; 2002. pages 23, 33, 87, 137, 181, 276, 285, 373.

8. Silveira JA, Rabelo EM, Ribeiro MF. Molecular detection of tick-borne pathogens of the family Anaplasmataceae in Brazilian brown brocket deer (Mazama gouazoubira, Fischer, 1814) and marsh deer (Blastocerus dichotomus, Illiger, 1815). Transbound Emerg Dis. 2012;59(4):353-60.

9. Hairgrove T, Schroeder ME, Budke CM, Rodgers S, Chung C, Ueti MW, et al. Molecular and serological in-herd prevalence of Anaplasma marginale infection in Texas cattle. Prev Vet Med. 2015;119(1-2):1-9.

10. Anderson BE, Sumner JW, Dawson JE, Tzianabos T, Green CR, Olson JG. Detection of the etiologic agent of human ehrlichiosis by polymerase chain reaction. J Clin Microbiol. 1992;30:775-80.
11. Chen SM, Dumler JS, Bakken JS, Walker DH. Identification of a granulocy to tropic Ehrlichia species as the etiologic agent of human disease. J Clin Microbiol. 1994;32:589-95.

12. Hapunik J, Víchová B, Karbowiak G, Wita I, Bogdaszewski M, Pet'ko B. Wild and farm breeding cervids infections with Anaplasma phagocytophilum. Ann Agric Environ Med. 2011;18(1):73-7.

13. Harvey JW, Simpson CF, Gaskin JM. Cyclic thrombocytopenia induced by a Rickettsi-like agent in dogs. J Infect Dis. 1978;137:182-8.

14. Kontos VI, Papadopoulos O, French TW. Natural and experimental canine infections with a Greek strain of Ehrlichia platy. Vet Clin Pathol. 1991;20:101-5.

15. Ramos RA, Latrofa MS, Giannelli A, Lacasella V, Campbell BE, Dantas-Torres F, et al. Detection of Anaplasma platys in dogs and Rhipicephalus sanguineus group ticks by a quantitative real-time PCR. Vet Parasitol. 2014;205(1-2):285-8.

16. Inokuma H, Ohno K, Onishi T, Raoult D, Brouqui P. Detection of ehrlichial infection by PCR in dogs from Yamaguchi and Okinawa Prefectures. Japan J Vet Med Sci. 2001;63:815-7.

17. Latrofa MS, Dantas-Torres F, Giannelli A, Otranto D. Molecular detection of tick-borne pathogens in Rhipicephalus sanguineus group ticks. Ticks Tick Borne Dis. 2014;5(6):943-6.

18. Xinmin He. Ecological distribution and number distribution of camel's species in China. Zhong guo xu mu ye xinxi wang. 2013. http://www.caaa.cn/show/newsarticle.php? ID = 299333.

19. Fassi-Fehri MM. Diseases of camels. Rev sci tech Off int Epiz. 1987;6(2):337-54.

20. Wernery U, Kinne J, Schuster RK. Camelids infectious disorders [C]. OIE. 2014;74-83.

21. Alsaad KM. Clinical, hematology and biochemical studies of anaplasmosis in Arabian one-humped Camels (Camelus dromedaries). J Anim Vet Advan. 2009;8(11):2106-9.

22. Sudan V, Sharma RL, Borah MK. Subclinical anaplasmosis in camel (Camelus dromedarius) and its successful therapeutic management. J Parasit Dis. 2014;38(2):163-5.

23. Ghafar MW, Shobrak MY. Molecular detection and characterization of Anaplasma phagocytophilum, the causative agent of human granulocytic anaplasmosis, in some animals suspected to be competent reservoirs in Taif district, Kingdom of Saudi Arabia. Life Science Journal. 2014;11(6):63-9.

24. Ben Said M, Belkahia H, Sayahi L, Aloui M, Jemli MH, Hadj Mohamed B, et al. First serological study of the prevalence of Anaplasma phagocytophilum in dromedary (Camelus dromedarius) in Tunisia. Bull Soc Pathol Exot. 2013. doi:10.1007/s13149-013-0323-8.

25. Pan H, Yuhai M, Shide T, Yang S, Bohai W, Xiangrui C. Canine ehrlichiosis caused simultaneously by Ehrlichia canis and Ehrlichia platys. Microbiol Immunol. 2000;44:737-9.

26. Liu Z, Ma M, Wang Z, Wang J, Peng Y, Li Y, et al. Molecular survey and genetic identification of Anaplasma species in goats from central and southern China. Appl Environ Microbiol. 2012;78:464-70.

27. Yang J, Liu Z, Guan G, Liu Q, Li Y, Chen Z, et al. Prevalence of Anaplasma phagocytophilum in ruminants, rodents and ticks in Gansu, north-western China. J Med Microbiol. 2013;62(Pt 2):254-8.

28. Li Y, Chen Z, Liu Z, Liu J, Yang J, Li Q, et al. Molecular survey of Anaplasma and Ehrlichia of red deer and sika deer in Gansu, China in 2013. Transbound Emerg Dis. 2015; doi:10.1111/tbed.12335. [Epub ahead of print].

29. Talleklint-Eisen L, Lane RS. Efficiency of drag sampling for estimating population sizes of Ixodes pacificus (Acari: Ixodidae) nymphs in leaf litter J Med Entomol. 2000;37:484-7.

30. Norval RA, Perr BD. Young AS. The epidemiology of Theileriosis in Africa: Academic; 1992

31. Teng KF, Jiang ZJ. Economic Insect Fauna of China. Fasc 39, Acari: Ixodidae. Bejing: Science Press; 1991. p. 158-81.

32. Dantas-Torres F, Latrofa MS, Annoscia G, Giannelli A, Parisi A, Otranto D. Morphological and genetic diversity of Rhipicephalus sanguineus sensu lato from the New and Old Worlds. Parasit Vectors. 2013;6:213.

33. Kawahara M, Rikihisa Y, Lin Q, Isogai E, Tahara K, Itagaki A, et al. Novel genetic variants of Anaplasma phagocytophilum, Anaplasma bovis, Anaplasma centrale, and a novel Ehrlichia sp. in wild deer and ticks on two major islands in Japan. Appl Environ Microbiol. 2006;72(2):1102-9.

34. Torina A, Agnone A, Blanda V, Alongi A, D'Agostino R, Caracappa S, et al. Development and validation of two PCR tests for the detection of and differentiation between Anaplasma ovis and Anaplasma marginale. Ticks Tick Borne Dis. 2012;3(5-6):283-7.

35. Inokuma H, Fujii K, Matsumoto K, Okuda M, Onishi T, Beaufils JP, et al. Determination of nucleotide sequences of groESL heat shock operon and 
citrate synthase gene (gltA) of Anaplasma (Ehrlichia) platys for phylogenetic and diagnostic studies. Clin Diagn Lab Immunol. 2002;9:1132-6.

36. Lima MLF, Soares PT, Ramos CAN, Araújo FR, Ramos RAN, Souza IIF, et al. Molecular detection of Anaplasma platys in a naturally infected cat in Brazil. Braz J Microbiol. 2010;41:381-5.

37. Cardoso L, Gilad M, Cortes HC, Nachum-Biala Y, Lopes AP, Vila-Viçosa MJ, et al. First report of Anaplasma platys infection in red foxes (Vulpes vulpes) and molecular detection of Ehrlichia canis and Leishmania infantum in foxes from Portugal. Parasit Vectors. 2015;8(1):756.

38. Maggi RG, Mascarelli PE, Havenga LN, Naidoo V, Breitschwerdt EB. Coinfection with Anaplasma platys. Bartonella henselae and Candidatus Mycoplasma haematoparvum in a veterinarian. Parasit Vectors. 2013;6:103.

39. Arraga-Alvarado CM, Qurollo BA, Parra OC, Berrueta MA, Hegarty BC, Breitschwerdt EB, et al. Molecular evidence of Anaplasma platys infection in two women from Venezuela. Am J Trop Med Hyg. 2014;91:1161-5.

40. Kamani J, Baneth G, Mumcuoglu KY, Waziri NE, Eyal O, et al. Molecular detection and characterization of tickborne pathogens in dogs and ticks from Nigeria. PLoS Negl Trop Dis. 2013;7(3), e2108.

\section{Submit your next manuscript to BioMed Central and take full advantage of:}

- Convenient online submission

- Thorough peer review

- No space constraints or color figure charges

- Immediate publication on acceptance

- Inclusion in PubMed, CAS, Scopus and Google Scholar

- Research which is freely available for redistribution 